University of Nebraska - Lincoln

DigitalCommons@University of Nebraska - Lincoln

Educational Psychology Papers and

Publications

Educational Psychology, Department of

May 2003

\title{
Relationships Among Relational Communication Processes and Perceptions of Outcomes in Conjoint Behavioral Consultation
}

\author{
Priscilla F. Grissom \\ North Carolina State University \\ William P. Erchul \\ North Carolina State University, william_erchul@ncsu.edu \\ Susan M. Sheridan \\ University of Nebraska-Lincoln, ssheridan2@unl.edu
}

Follow this and additional works at: https://digitalcommons.unl.edu/edpsychpapers

Part of the Educational Psychology Commons

\begin{abstract}
Grissom, Priscilla F.; Erchul, William P.; and Sheridan, Susan M., "Relationships Among Relational Communication Processes and Perceptions of Outcomes in Conjoint Behavioral Consultation" (2003). Educational Psychology Papers and Publications. 8.

https://digitalcommons.unl.edu/edpsychpapers/8

This Article is brought to you for free and open access by the Educational Psychology, Department of at DigitalCommons@University of Nebraska - Lincoln. It has been accepted for inclusion in Educational Psychology Papers and Publications by an authorized administrator of DigitalCommons@University of Nebraska - Lincoln.
\end{abstract}




\title{
Relationships Among Relational Communication Processes and Perceptions of Outcomes in Conjoint Behavioral Consultation
}

\author{
Priscilla F. Grissom and William P. Erchul \\ North Carolina State University
}

Susan M. Sheridan

University of Nebraska-Lincoln

\begin{abstract}
Conjoint behavioral consultation (CBC), an extension of behavioral consultation, considers home and school settings when conceptualizing a student's difficulty (Sheridan, Kratochwill, \& Bergan, 1996). A relational communication perspective was adopted to examine interpersonal control (i.e., attempts to influence and successfully influence) and its relationship to CBC outcomes. Consultant, teacher, and parent influence was measured in 20 CBC initial interviews using the Family Relational Communication Control Coding System (Heatherington \& Friedlander, 1987), and outcomes were assessed regarding the acceptability/effectiveness of $\mathrm{CBC}$, consultant effectiveness, and attainment of consultation goals. Results indicated that parental influence is associated with less favorable teacher ratings regarding model acceptability/effectiveness and less favorable parent ratings of goal attainment. Results further suggest that greater importance should be placed on parent behavior with respect to outcomes of CBC.
\end{abstract}

An extensive body of literature has examined the positive effects of parental involvement in a child's education, with several comprehensive reviews available (e.g., Christenson \& Conoley, 1992; Fine, 1980, 1989). A relatively

Correspondence should be addressed to William P. Erchul, Department of Psychology, North Carolina State University, Raleigh, NC 27695-7801.E-mail:william_erchul@ncsu.edu 
new model of consultation that has resulted from efforts to systematize parent involvement in education is conjoint behavioral consultation (CBC). Sheridan and Kratochwill (1992) defined CBC as "a structured, indirect form of service-delivery, in which parents and teachers are joined to work together to address the academic, social, or behavioral needs of an individual for whom both parties bear some responsibility" (p. 122).

The two major theoretical bases of CBC are behavioral and ecological systems theory (Sheridan, 1997; Sheridan, Kratochwill, \& Bergan, 1996). A reliance on these theoretical bases assumes that (a) change agents should focus on observable behavior and not hypothesized underlying causes of behavior, (b) considerable attention should be given to setting specific intervention goals and identifying important environmental influences on behavior, (c) evidence-based techniques should be used to change behavior, and (d) professionals working with child clients should recognize that a child's behavior affects, and is affected by, others within his or her ecological system. Bronfenbrenner's (1977) view of the mesosystem is particularly relevant to $\mathrm{CBC}$, as it focuses on the connectedness of the child's home and school microsystems.

There are two further assumptions implicit to $\mathrm{CBC}$. First, the relationship between a child's home and school involves cooperation and interaction, which implies that the responsibility for problem resolution is shared between these two systems. Second, a collaborative problem-solving model will be the most beneficial to achieving problem resolution. This approach allows each person who knows the child to share his or her knowledge and expertise; therefore, multiple perspectives are incorporated when considering possible interventions (Sheridan et al., 1996).

The process of $C B C$ is very similar to the process of behavioral consultation (Bergan \& Kratochwill, 1990), in that CBC unfolds in four stages that include three interviews. Specifically, $C B C$ is comprised of a conjoint problem identification interview (CPII), conjoint problem analysis interview (CPAI), conjoint treatment implementation phase (CTI), and conjoint treatment evaluation interview (CTEI). A detailed description of the goals and objectives within each stage, as well as other implementation issues, are found in Sheridan et al. (1996).

\section{CBC OUTCOME RESEARCH}

Several small- $n$ research studies have found CBC to be effective in changing client behavior. CBC's efficacy has been demonstrated in cases 
dealing with a range of difficulties including social withdrawal (Sheridan, Kratochwill, \& Elliott, 1990), failure to complete academic tasks (Galloway \& Sheridan, 1994), failure to complete homework assignments (Weiner, Sheridan, \& Jenson, 1998), disruptive play behaviors in children with attention deficit hyperactivity disorder (ADHD; Colton \& Sheridan, 1998), and nighttime fears (Sheridan \& Colton, 1994).

In response to certain methodological limitations associated with these studies, Sheridan, Eagle, Cowan, and Mickelson (2001) completed the first large-scale study of CBC outcomes. These researchers specifically assessed the effects of $C B C$ over a 4-year period. Thirty graduate students trained in $\mathrm{CBC}$ conducted $57 \mathrm{CBC}$ cases involving clients in kindergarten through ninth grade. The majority of the clients $(74 \%)$ were identified to have an academic or behavior-emotional disorder. Direct observational and subjective outcome data were collected. Direct observations of client target behaviors were recorded throughout $C B C$ by parents and teachers. Subjective outcomes, including treatment efficacy, goal attainment, treatment acceptability, and consultant effectiveness, were assessed at the conclusion of $C B C$. Integrity of the $C B C$ process and of treatment implementation was assessed. To analyze the efficacy of $C B C$, effect sizes for each case were generated. Multiple regression analyses were employed to determine if client age, case complexity, and symptom severity were related to effect size outcomes.

The results of the study indicated that the average effect size for client outcomes was $1.10(S D=1.07)$, and no differences existed between outcomes obtained in home and school settings. Regression analyses revealed that, with respect to school effect sizes, client age and symptom severity predicted outcomes relatively well. Parents and teachers reported high levels of acceptability and satisfaction with the $C B C$ experience. Consultants met an average of $83 \%$ of the CBC interview objectives, and teachers and parents reported measures of integrity for $71 \%$ of the treatment plans. Sheridan et al. (2001) concluded that these results support those of previous $C B C$ research that concluded $C B C$ to be an efficacious and highly acceptable model of service delivery.

\section{CBC PROCESS RESEARCH}

Although research on the outcomes of $\mathrm{CBC}$ is accumulating, considerably less research has examined the interpersonal processes that occur within CBC. One such study is Sheridan's (1997) initial examination of CBC verbal interactions. Specifically, consultant and consultee messages contained in 
six CPIIs were coded using the Consultation Analysis Record (CAR; Bergan \& Tombari, 1976), and these statements were compared to teacher-only behavioral consultation data reported previously by other researchers. Sheridan hypothesized that, in comparing $C B C$ with behavioral consultation, in CBC: (a) more statements concerning the child's environment would be made, (b) parents would participate as much as teachers, (c) teachers would speak less, and (d) consultants would ask more questions.

Sheridan's (1997) results suggested that statements regarding the child's environment are not more frequent in $C B C$, as in both types of consultation these statements were minimal. In $\mathrm{CBC}$, the amount of parent verbalizations was slightly higher than teacher verbalizations $(32 \%$ vs. $24 \%$, respectively). Furthermore, teachers in CBC verbalized proportionally less than they did in behavioral consultation; teachers emitted $24 \%$ of all verbalizations in $\mathrm{CBC}$ and $74 \%$ in teacher-only behavioral consultation. Finally, consultants were found to make $56 \%$ of all statements in $\mathrm{CBC}$, compared with $26 \%$ in teacher-only consultation. Sheridan concluded that consultants appeared to control more of the discussion in $C B C$, suggesting that the presence of additional consultees may lead consultants to provide more structure to the discussion.

Sheridan, Meegan, and Eagle (2002) examined the communicative processes of influence and involvement in CBC. The purpose of their study was to (a) identify the nature of consultant and consultee speech acts, (b) examine the communicative function of interchanges between participants, and (c) explore the relationships between participant exchanges and CBC outcomes. The authors used the Psychosocial Processes Coding Scheme (PPCS) (Leaper, 1991) to categorize the function of speech acts as being either influence or involvement. Speech acts that influence can be either direct or nondirect. Speech acts characterized as involvement are either affiliative or distancing, depending on the speaker's intent to move closer to, or to separate from, the other person. Therefore, using the PPCS, the following four combinations are possible: controlling (direct and distancing), withdrawing (nondirect and distancing), collaborative (direct and affiliative), and obliging (nondirect and affiliative). Outcomes of $C B C$ were measured through subjective as well as objective measures. The results of this study suggested that the communicative process in $\mathrm{CBC}$ is highly collaborative, with the next most frequent category of speech acts being obliging. Sheridan et al. (2002) concluded, "The nature of interactions and the social context in the CBC samples was overwhelmingly affiliative, characterized by a reciprocal 'give and take,' cooperative conversational style" (p. 316). 


\section{RELATIONAL COMMUNICATION AND CBC}

In this study, verbal interactions within $\mathrm{CBC}$ were examined using a relational communication framework. ${ }^{1}$ In contrast to content-based frameworks, such as the CAR, a relational communication perspective focuses on the process of communication (i.e., the how rather than the what). In particular, this study uses the Family Relational Communication Control Coding System (FRCCCS; Heatherington \& Friedlander, 1987) to investigate the process of CBC. The FRCCCS was created by modifying a dyadic relational communication control coding system (RCCCS) developed originally by Rogers and Farace (1975). The FRCCCS extension of the RCCCS allows one to analyze relational communication as it unfolds in groups of three or more persons. Given the complexity of the FRCCCS, a brief summary of its basic components is presented next.

The FRCCCS considers a pair of sequential messages as the principal unit of analysis. Each message is assigned a code that specifies speaker, target, message format (e.g., assertion, question), and response mode (e.g., support, answer, instruction). When this code is given, a control dimension is assigned to each message based on the combination of the format and response mode codes. ${ }^{2}$ The three possible control codes are: one-up ( 1$)$, indicating a move toward gaining control; one-down ( $\bullet$ ), indicating an acceptance of another's control; and one-across ( $\bullet$ ), indicating neither an attempt to gain nor accept control.

The third and final step of the coding system is to assign the control codes of sequential messages, which reveals the nature of transactional control. Transactions may be considered symmetrical, which are indicated by directionally identical codes $(\Lambda$ or $\cdots$ ); complementary, which have directionally opposite codes $(\Lambda$ or $\nabla)$ or transitory, which are indicated by the presence of a one-across code $(\omega, \cdots, \cdots$, or $\leftrightarrow)$. In complementary transactions, the speakers' behaviors are opposites, with one speaker offering a definition of the relationship that is accepted by the other speaker. In symmetrical transactions, behaviors are parallel, and the speakers demonstrate similar definitions of the relationship. Transitory

\footnotetext{
'Although the history and concepts of relational communication are critical to understand the background of this research, these topics are beyond the scope of this article. The interested reader is referred to Erchul et al. (1999) for a more detailed discussion of relational communication and its application to CBC.

${ }^{2}$ The assignment of control codes to specific messages within the FRCCCS is specified in Table 3 of Erchul et al. (1999).
} 
transactions refer to interactions in which one speaker minimizes or neutralizes the issue of control.

The coding system further allows for two indices of control to be calculated, one individual and one relational (Courtright, Millar, \& Rogers-Millar, 1979; Rogers-Millar \& Millar, 1979). Domineeringness, an individual measure, is defined as the number of one-up messages by speaker A divided by the total number of A's messages. A high domineeringness score for speaker $A$ indicates frequent attempts to control by speaker A regardless of the response by speaker B. Dominance for speaker $A$ refers to the proportion of one-up messages by speaker $A$ that speaker $B$ responds to with a one-down message. $A$ high dominance score for speaker $A$ indicates that speaker $B$ has accepted A's attempts to control the conversational process. This variable is considered relational because it considers the interaction between the two speakers.

Perhaps because $C B C$ is a relatively new service-delivery model, there is only one published study that examined CBC employing the FRCCCS. Erchul et al. (1999) used the FRCCCS to code 9,696 individual messages across the three interviews (CPII, CPAI, and CTEI) that constituted four CBC cases. Using the relational control research findings that existed for behavioral consultation (e.g., Erchul, 1987; Erchul \& Chewning, 1990; Erchul, Covington, Hughes, \& Meyers, 1995), they hypothesized that consultants would demonstrate higher levels of domineeringness and dominance than teachers or parents. However, results suggested that attempts to influence the process of $C B C$ (i.e., domineeringness) were generally similar across participants. Differences existed in that consultants tended to exhibit more domineeringness toward parents and teachers than parents and teachers exhibited toward consultants. In addition, a comparison of average dominance scores across participants suggested that no participant was highly dominant (i.e., influential). However, consultees generally exhibited more dominance than did consultants. When examining control patterns across interviews, there was little overall variability with respect to domineeringness scores. Dominance scores, however, suggested that the pattern of teacher-to-consultant exchanges varied across interviews; across the four cases, this dyad demonstrated the greatest variability in dominance $(S D=0.20)$.

Erchul et al. (1999) concluded that, when compared with the relational communication patterns displayed in teacher-only behavioral consultation, the relationships within CBC appear to be more symmetrical and reciprocal. Unlike the findings of Erchul (1987), which characterized the traditional behavioral consultation consultant-consultee relationship as complementary, CBC participants showed pattems of relational control that were strikingly similar (i.e., symmetrical). 


\section{REINTERPRETING OLD TERMINOLOGY}

Before describing this study, it is necessary to revisit the issue of negative connotations surrounding several relational communication constructs. As noted previously (Erchul, 1987, 1992a, 1999; Erchul et al., 1999), domineeringness and dominance have very specific operational meanings and carry no obvious negative associations within the relational communication research literature. However, use of these terms has resulted in some controversy within the consultation literature. Some authors, for example, have suggested that a construct termed dominance must be conceptually incompatible with collaboration (Henning-Stout, 1993) and that verbal interaction coding systems that measure domineeringness and dominance within consultation must be "simplistic" (Brown, 1993).

Given an apparent lack of acceptance of domineeringness and dominance, Erchul et al. (1999) reinterpreted these constructs for further use in consultation research. Table 1 shows that the current view of domineeringness is one of directiveness and/or an attempt to influence relationship definitions in consultation. Dominance is considered the successful demonstration of influencing relationships in consultation. Although this contemporary view may be extending beyond the original operational definitions of domineeringness and dominance (as well as the proper study of persuasion and influence), it does seemingly place the two constructs more appropriately within the consultation research literature (Erchul et al., 1999). Along these lines, school psychological consultation is increasingly regarded as an interpersonal influence process (Hughes, 1992; O'Keefe \& Medway, 1997).

Expanding on these ideas, Table 2 provides examples of parent dominance (i.e., one-up, one-down message exchanges) taken from verbatim $C B C$ transcripts. These examples may serve to remind the reader that the construct of dominance is a more subtle than overtly blatant aspect of interpersonal communication (Erchul, 1992a), and that it embodies an interpersonal perspective on consultation research (Erchul, Hughes, Meyers, Hickman, \& Braden, 1992) because its definition depends on the subsequent response of a second $C B C$ participant.

\section{PURPOSE AND HYPOTHESES}

Previous researchers have systematically studied processes and outcomes of CBC to some extent (e.g., Colton \& Sheridan, 1998; 


\section{TABLE 1}

Explanation of Key Variables Used Originally in Relational Communication Research and Applied Later to Consultation Research

Domineeringness

Dominance

Definition within relational communication research literature

Less acceptable interpretation of variable within consultation research literature

More acceptable interpretation of variable within consultation research literature
An individual measure of a person's attempts to control and/or define a relationship. Operationally defined as the number of a person's one-up messages divided by the total number of his or her messages (Courtright et al., 1979; Rogers-Millar \& Millar, 1979).

One's attempt to control the process of consultation (Erchul, 1987).

"An index of a person's directiveness or his or her attempts to structure or define relationships in consultation" (Erchul et al., 1999, p. 125).
A dyadic measure of relational control. For Person A, operationally defined as the proportion of one-down messages given by Person B to all one-up messages offered by A (Courtright et al., 1979; Rogers-Millar \& Millar, 1979).

One's demonstrated, successful control of the process of consultation (Erchul, 1987).

"An index of a person's demonstrated influence or success in defining relationships in consultation" (Erchul et al., 1999, p. 125).

TABLE 2

Examples of Parent Dominance ${ }^{\mathrm{a}}$ From CBC Transcripts

Speaker: Message

Control Code

Example 1

Parent: "Can you pick just like inattention? Is that too broad?"

Consultant: "That's really quite broad."

One-up

Comple 2

Consultant: "Does he need your help or grandmother's help?"

Parent: (Interrupts) "Yeah, yeah he does."

Consultant: "Good."

One-down

One-up

One-up

One-down

Example 3

Consultant: "What are some things that Jack is good at? Like, what are some of his strengths?"

Parent: "He really writes good. I mean I don't know what. Is that what you mean?"

Consultant: "Yeah, I want to know a lot of good things about him."

One-up

One-up

One-down

Example 4

Parent: (Interrupts) "That's not necessarily the

One-up sight words then, is that?"

Teacher: "Well, it is but, it is different from what

One-down he does with Miss Smith."

Note. $\mathrm{CBC}=$ Conjoint behavioral consultation.

'Parent dominance is defined as the proportion of a parent's one-up messages that a consultant or teacher responds to with a one-down message. 
Galloway \& Sheridan, 1994; Sheridan, 1997; Sheridan \& Colton, 1994; Sheridan et al., 1990; Weiner et al., 1998) although less research has examined the relationships between these variables. Process variables included in this study (i.e., domineeringness and dominance) focus on relational communication within $\mathrm{CBC}$. As described in Table 1, these variables describe an individual's attempts to influence, and his or her success in influencing, relationships between CBC participants. Outcome variables in this study were consultee perceptions of: (a) the acceptability/effectiveness of $C B C$ as a treatment, as measured by the Behavior Intervention Rating Scale-Revised (BIRS-R; Von Brock \& Elliott, 1987); (b) the effectiveness of the CBC consultant, as measured by the Consultant Evaluation Form (CEF) (Erchul, 1987); and (c) client progress toward consultation goals, as measured by Goal Attainment Scaling (GAS; Kiresuk, Smith, \& Cardillo, 1994).

The purpose of this investigation was to examine the relationship between domineeringness and dominance and the three outcome variables. Based on prior findings in behavioral consultation and $C B C$, the following hypotheses were advanced: (a) there will be significant, positive correlations between consultant domineeringness and dominance and parent and teacher ratings on the three outcome measures; (b) there will be significant, negative correlations between teacher domineeringness and dominance and parent and teacher ratings on the three outcome measures; and (c) there will be significant, negative correlations between parent domineeringness and dominance and parent and teacher ratings on the three outcome measures.

\section{METHOD}

\section{Participants}

Consultants. The $20 \mathrm{CBC}$ cases involved 16 consultants who were advanced school psychology graduate students affiliated with University of Utah. These 20 cases were selected from a larger set of cases because they were considered to have the most complete outcome data. Twelve consultants were women. The mean age of the consultants was 31.9 years $(S D=8.1)$. With respect to educational level, $50 \%$ of the consultants held bachelor's degrees, and 50\% held master's degrees. Fourteen consultants were Caucasian.

Consultees. The consultees were 23 school-based professionals and 20 parents. Of the professionals who served as consultees, 20 were regular ed- 
ucation teachers, and 3 were special education teachers. Nineteen teachers were women. The teachers' mean age was $45.2(S D=7.9)$, and their mean years of experience was $14.9(S D=10.1)$. The educational level of teachers was diverse; $54.5 \%$ held master's degrees, $40.9 \%$ had bachelor's degrees, and $4.5 \%$ had specialist or doctoral degrees. Twenty-two teachers were Caucasian. Only three teachers reported having prior experience with consultation.

The mean age of the 20 parents was 37.4 years $(S D=8.0)$, and 2 of the parents reported an ethnicity other than Caucasian. Sixteen parents were women. Four parents held bachelor's or master's degrees; all others had high school degrees.

Clients. The 20 clients were elementary and middle school students who were referred for consultation by a teacher or parent. Six students were diagnosed with a behavioral disorder; four, a learning disability; two, attention deficit hyperactivity disorder (ADHD); and three, various disorders that included sleep disorder, Asperger's syndrome, and autism. Five students did not have formal diagnoses, and consultation was thus implemented as a prereferral intervention strategy. The mean age of the clients was 8.9 years $(S D=2.5)$. Twelve students were boys. Hifteen were Caucasian, and all were English speakers.

\section{Measures}

Process variables. The FRCCCS (Heatherington \& Friedlander, 1987) was employed to study patterns of relational communication in CBC. As noted earlier, as a relational coding system, the FRCCCS describes the verbal process of consultation rather than its content. Two measures of relational communication, domineeringness and dominance, were calculated for each consultant and consultee. To calculate these measures, the control codes (e.g., one-up, one-down) for each message and pair of messages are used. Domineeringness, an individual variable, is operationally defined as the ratio of speaker A's one-up messages to the total number of A's messages. Dominance, a dyadic or relational variable, is operationally defined as the number of one-up messages by speaker $A$ that are responded to with one-down messages by speaker B. Erchul et al. (1999) noted that "adequate reliability and validity exist for the FRCCCS" (p. 132). 
Outcome variables. Ratings made by teachers and parents on the Consultee Final Perceptions Form (CEFPF) (Sheridan \& Erchul, 1995) were used to derive the three outcome measures. The CEFPF, which consultees completed at the end of $\mathrm{CBC}$, is a relatively lengthy questionnaire used to assess a range of consultee perspectives on processes and outcomes of consultation. All three outcomes measures are embedded within the CEFPF.

The Behavior Intervention Rating Scale (BIRS; Elliott \& Von Brock Treuting, 1991; Von Brock \& Elliott, 1987) is a 24-item instrument that has three factors measuring treatment acceptability, effectiveness, and time to effect. Because the BIRS was adapted to include the words "model of consultation" rather than "intervention," we refer to this measure as the Behavior Intervention Rating Scale-Revised (BIRS-R). The BIRS has been found to be a valid measure of treatment acceptability and treatment effectiveness (Elliott \& Von Brock Treuting, 1991), and the complete 24-item scale was used in this study. Ratings are made by consultees on a 6-point rating scale, with higher scores indicating greater acceptability/effectiveness. Elliott and Von Brock Treuting reported a coefficient alpha of 0.97 for the BIRS total score, indicating high internal consistency.

The CEF (Erchul, 1987) is a 12-item instrument that measures consultee perceptions of consultant effectiveness and/or satisfaction with consultation services. The CEF has been used in numerous consultation studies (e.g., Erchul \& Chewning, 1990; Erchul et al., 1992; Kratochwill, Elliott, \& Busse, 1995; Kratochwill, Sheridan, Carrington Rotto, \& Salmon, 1991; Sheridan et al., 2001; Witt, Erchul, McKee, Pardue, \& Wickstrom, 1991). Consultees rate items on a 7-point rating scale, and an average of these ratings is reported as the CEF score for each consultant. Higher scores indicate a more favorable evaluation of a consultant's effectiveness and/or increased satisfaction with consultation. Erchul et al. (1995) documented the use of the CEF with a sample of 129 consultees and noted a mean of $74.6(S D=10.5$; scores were summed rather than averaged) and a coefficient alpha of 0.94 .

GAS (Kiresuk et al., 1994) is a single-item rating that assesses consultee perceptions of goal attainment. GAS has been used previously in consultation research (e.g., Busse, Kratochwill, \& Elliott, 1995; Kratochwill et al., 1995; Sheridan et al., 2001). A GAS rating is made by a consultee using a 5-point rating scale that ranges from -2 (situation got significantly worse) to +2 (situation got significantly better). For the purpose of this study, a constant of 3 was added to GAS ratings, making it a 1-to-5 scale. Cardillo and Smith (1994) concluded in their 
review that numerous studies support the reliability and validity of GAS.

\section{Procedure}

CBC consultants were trained to mastery using a model described by Sheridan, Salmon, Kratoch will, and Carrington Rotto (1992). Following the training, they were placed in elementary and middle schools to provide consultative services to the teachers and parents of mainstreamed students. Consultation referrals were initiated through meetings with school-based teams, meetings with the school psychologists, or parent referrals. Following the referral, a consultant implemented the $\mathrm{CBC}$ model as outlined by Sheridan et al. (1996), and each interview was audiotaped and transcribed. For the data set to be reported, the overall integrity of the CBC interview process was $94 \%$. Consultants were provided structured supervision by the third author or her advanced graduate students, using Sheridan et al.'s (1992) model. Consultees completed the BIRS-R, CEF, and GAS following the CTEI.

The coding of transcribed interviews was completed by trained coders at North Carolina State University. The approximately $30 \mathrm{hr}$ of group and individual training on the FRCCCS included instruction in four modifications to the original coding system, which had been implemented in previous research studies (Erchul, 1987; Erchul et al., 1999). First, the primary author specified the direct and indirect targets on all transcripts because of the difficulty in consistently recognizing voices on audiotapes. Second, the original category of "unsuccessful talkover" was eliminated because Rogers and Farace (1975) did not use this category in their original research, and the variable quality of the audiotapes often caused difficulty in determining if a talkover was unsuccessful. Third, an open question-extension message was assigned a one-up control code rather than a one-down code. This modification is supported by previous research that suggests questions are a speaker's attempt to control a conversation, which then would be more accurately represented as a one-up message (Erchul et al., 1999). Finally, the coders considered no more than four previous messages when linking pairs of messages to calculate dominance scores. The original FRCCCS, which has been applied to interactions that may involve larger groups of participants, does not impose a limit on the pairing of noncontiguous messages. It was thought this modification would increase the reliability of message pairings.

For each pair of coders, Cohen's kappa was calculated, and acceptable levels of reliability were established before coders were allowed to 
proceed with coding the study's interviews. Acceptable levels of Cohen's kappa were determined by reviewing kappas in published literature, which ranged from 0.52 to $0.98(M=.81$; Erchul, 1987; Erchul et al., 1999; Heatherington, 1985; Heatherington \& Friedlander, 1989; Tracey \& Miars, 1986). Based on 1,899 coded messages, the mean kappa for the message format code was 0.94 , and the mean kappa for the response mode code was 0.84 . These kappas are comparable to those reported previously.

Thirty-minute segments of each CPII transcript were marked as the sample of the interview to be coded. The segments were determined by excluding the first $10 \mathrm{~min}$ of each interview; the next $30 \mathrm{~min}$ were used as the coded segment, and the remainder of the interview was excluded. This time sampling was used to reduce the overall time needed to code an entire interview. Prior research demonstrated that time sampling provides for reliable estimates of domineeringness and dominance (Erchul \& Schulte, 1990). Coders coded each of the messages within the 30-min segment of the CPIIs using transcripts and audiotapes. Domineeringness and dominance scores then were calculated for all participants.

\section{RESULTS}

\section{Descriptive Statistics}

Measures of processes in $C B C$. Table 3 presents the means and standard deviations of domineeringness and dominance by dyad for all participants. Consultants displayed the highest levels of domineeringness (number of one-up messages by speaker A divided by the total number of speaker A's messages), and teachers and parents displayed nearly identical, but lower, levels of domineeringness. With respect to dominance (proportion of one-up messages by speaker A responded to with one-down messages by speaker B), there was greater similarity among participants; that is, with the exception of teacher-to-parent dominance (0.28), all other dyads had dominance scores from 0.44 to 0.50 . One may conclude from these data that although there is some variability in attempts to influence the direction of the conversation within CBC (i.e., domineeringness), it seems that, with some qualification, there is shared influence in the relationship.

Measures of outcomes in $C B C$. Table 4 presents the means and standard deviations of the outcome variables: teacher and parent ratings on the BIRS-R, GAS, and CEF. Mean scores on all outcomes are well above the mean for each scale, suggesting that teachers and parents perceived (a) $\mathrm{CBC}$ 
TABLE 3

Means and Standard Deviations for Consultant and Consultee Domineeringness ${ }^{A}$ and Dominance ${ }^{b}$ Scores

\begin{tabular}{lll}
\hline $\begin{array}{ll}\text { Measure } \\
\text { Consultant to teacher }\end{array}$ & $\mathrm{M}$ & $\mathrm{SD}$ \\
\hline $\begin{array}{l}\text { Domineeringness } \\
\text { Dominance }\end{array}$ & 0.40 & 0.15 \\
$\begin{array}{l}\text { Consultant to parent } \\
\text { Domineeringness }\end{array}$ & 0.50 & 0.20 \\
$\quad$ Dominance & 0.39 & 0.11 \\
Teacher to consultant & 0.49 & 0.21 \\
$\quad$ Domineeringness & & \\
$\quad$ Dominance & 0.23 & 0.11 \\
Teacher to parent & 0.49 & 0.27 \\
$\quad$ Domineeringness & & \\
$\quad$ Dominance & 0.34 & 0.21 \\
Parent to consultant & 0.28 & 0.23 \\
$\quad$ Domineeringness & & \\
$\quad$ Dominance & 0.24 & 0.13 \\
Parent to teacher & 0.52 & 0.23 \\
$\quad$ Domineeringness & & \\
Dominance & 0.35 & 0.24 \\
\hline
\end{tabular}

${ }^{\mathrm{a}}$ Domineeringness is defined as the number of one-up messages by speaker $A$ divided by the total number of $A^{\prime} s$ messages. "Dominance for speaker $A$ is defined as the proportion of one-up messages by speaker A that speaker B responds to with a one-down message. "Within-person domineeringness and dominance proportions do not sum to 1.0 because they do not consider a person's one-across and one-down messages.

as an acceptable and effective model of service delivery, (b) significant client improvement to have occurred, and (c) the $\mathrm{CBC}$ consultant as effective.

\section{The Relationship Between Process Variables and CBC Outcomes}

To reduce the possibility of Type I error, the alpha level was set at 0.025 , one-tailed. Table 5 presents the intercorrelational matrix for relationships between consultant, teacher, and parent domineeringness and the six outcome measures. None of these correlations was found to be significant. 
Presented in Table 6 is the intercorrelation matrix depicting the relationships between consultant, teacher, parent dominance, and outcome measures. Using an alpha level of 0.025 , three of the correlations were found to be significant. Parent-to-consultant dominance correlated significantly and negatively with teacher ratings on the BIRS-R, $r(19)=$ $-.49, p=.01$. This finding suggests that as parents exhibit more successful influence in the parent-consultant dyad, teachers report less favorable ratings of the acceptability and effectiveness of CBC. Parent-to-consultant dominance also correlated significantly and negatively with parent ratings on the GAS, $r(14)=-.61, p=.01$. In addition, parent-to-teacher dominance correlated significantly and negatively with parent scores on the GAS, $r(14)=-.58, p=.01$. The two latter findings suggest that as parents' influence over teachers and consultants increases, parental ratings of children's goal attainment within $\mathrm{CBC}$ are less favorable.

\section{DISCUSSION}

Following a line of process-outcome research conducted by Erchul and his colleagues that focused on dyadic behavioral consultation with teachers, this study was an initial attempt to link indices of relational communication within $C B C$ to several perceived outcomes of $C B C$. Based on this prior research, it was predicted that consultant influence within $C B C$ would be related to positive consultation outcomes, and consultee (i.e., teacher and parent) influence would be related to negative outcomes. The study's

TABLE 4

Means and Standard Deviations for Consultant and Consultee Outcome Measures

\begin{tabular}{lll}
\hline Measure & $\mathrm{M}$ & $\mathrm{SD}$ \\
\hline BIRS-R $^{\mathrm{A}}$ & & \\
Teacher & 5.02 & 0.90 \\
Parent & 5.22 & 1.00 \\
GAS $^{\mathrm{b}}$ & & \\
Teacher & 4.16 & 0.83 \\
Parent & 4.27 & 0.46 \\
CEF & & \\
Teacher & 6.39 & 0.64 \\
Parent & 5.99 & 1.13 \\
\hline
\end{tabular}

Notes. BIRS-R = Behavior Intervention Rating Scale-Revised; GAS = Goal Attainment Scaling; $\mathrm{CEF}=$ Consultant Evaluation Form.

"Potential range of scores is 1 to 6. "Potential range of scores is 1 to 5. 'Potential range of scores is 1 to 7 . 
TABLE 5

Intercorrelations Between Domineeringness Scores and Outcome Measures $(n=20)$

\begin{tabular}{lrrrrrr}
\hline Measure & $\begin{array}{c}\text { Consultant } \\
\text { to Teacher }\end{array}$ & $\begin{array}{c}\text { Consultant } \\
\text { to Parent }\end{array}$ & $\begin{array}{c}\text { Teacher to } \\
\text { Consultant }\end{array}$ & $\begin{array}{c}\text { Teacher to } \\
\text { Parent }\end{array}$ & $\begin{array}{c}\text { Parent to } \\
\text { Consultant }\end{array}$ & $\begin{array}{c}\text { Parent to } \\
\text { Teacher }\end{array}$ \\
\hline $\begin{array}{l}\text { BIRS-R } \\
\text { Teacher }\end{array}$ &.$- .35( \pm .39)$ & $.18( \pm .43)$ & $-.03( \pm .45)$ & $.07( \pm .45)$ & $.22( \pm .43)$ & $.35( \pm .39)$ \\
$\begin{array}{l}\text { Parent } \\
\text { GAS }\end{array}$ & $-.12( \pm .46)$ & $.10( \pm .46)$ & $-.04( \pm .46)$ & $.00( \pm .46)$ & $.01( \pm .46)$ & $.01( \pm .46)$ \\
$\quad \begin{array}{l}\text { Teacher } \\
\text { Parent }\end{array}$ &.$- .34( \pm .41)$ & $.08( \pm .46)$ & $.01( \pm .46)$ & $.09( \pm .46)$ & $.00( \pm .46)$ & $.26( \pm .43)$ \\
CEF & $.07( \pm .52)$ & $-.25( \pm .49)$ & $.14( \pm .51)$ & $-.14( \pm .51)$ & $.35( \pm .46)$ & $.15( \pm .51)$ \\
$\quad \begin{array}{l}\text { Teacher } \\
\text { Parent }\end{array}$ & $-.34( \pm .40)$ & $-.02( \pm .45)$ & $.21( \pm .43)$ & $.28( \pm .42)$ & $.27( \pm .42)$ & $.46( \pm .36)$ \\
\hline
\end{tabular}

Notes. Entries in parentheses reflect $97.5 \%$ confidence interval bands around reported correlation coefficients. BIRS-R = Behavior Intervention Rating Scale-Revised; GAS = Goal Attainment Scaling; $\mathrm{CEF}=$ Consultant Evaluation Form.

TABLE 6

Intercorrelations Between Dominance Scores and Outcome Measures $(n=20)$

\begin{tabular}{lcccccc}
\hline Measure & $\begin{array}{c}\text { Consultant } \\
\text { to Teacher }\end{array}$ & $\begin{array}{c}\text { Consultant } \\
\text { to Parent }\end{array}$ & $\begin{array}{c}\text { Teacher to } \\
\text { Consultant }\end{array}$ & $\begin{array}{c}\text { Teacher to } \\
\text { Parent }\end{array}$ & $\begin{array}{c}\text { Parent to } \\
\text { Consultant }\end{array}$ & $\begin{array}{c}\text { Parent to } \\
\text { Teacher }\end{array}$ \\
\hline $\begin{array}{l}\text { BIRS-R } \\
\text { Teacher }\end{array}$ & $-.02( \pm .45)$ & $.11( \pm .44)$ & $.15( \pm .44)$ & $-.33( \pm .40)$ & $-.49( \pm .34)^{*}$ & $-.24( \pm .42)$ \\
$\quad \begin{array}{l}\text { Parent } \\
\text { AS }\end{array}$ & $.17( \pm .45)$ & $.14( \pm .45)$ & $-.02( \pm .46)$ & $.22( \pm .44)$ & $.04( \pm .46)$ & $.35( \pm .41)$ \\
$\quad \begin{array}{l}\text { Teacher } \\
\text { Parent }\end{array}$ & $.07( \pm .46)$ & $.26( \pm .43)$ & $.20( \pm .44)$ & $-.26( \pm .43)$ & $-.34( \pm .41)$ & $-.23( \pm .44)$ \\
CEF & $-.44( \pm 4)$ & $-.40( \pm .44)$ & $-.28( \pm .48)$ & $-.28( \pm .48)$ & $-.62( \pm .32)^{*}$ & $-.58( \pm .35)^{*}$ \\
$\quad$ Teacher & $.10( \pm .44)$ & $-.07( \pm .45)$ & $.08( \pm .47)$ & $-.37( \pm .39)$ & $-.22( \pm .43)$ & $-.04( \pm .45)$ \\
Parent & $-.09( \pm .45)$ & $-.10( \pm .45)$ & $-.17( \pm .44)$ & $-.06( \pm .45)$ & $-.33( \pm .34)$ & $-.16( \pm .44)$ \\
\hline
\end{tabular}

Notes. Entries in parentheses reflect $97.5 \%$ confidence interval bands around reported correlation coefficients. BIRS-R = Behavior Intervention Rating Scale-Revised; GAS = Goal Attainment Scaling; $\mathrm{CEF}=$ Consultant Evaluation Form.

${ }^{*} p<.025$, one-tailed.

methodology was to correlate scores on the relational communication variables of domineeringness and dominance with participant ratings on three outcome measures (i.e., BIRS-R, CEF, and GAS) for $20 \mathrm{CBC}$ cases.

The first hypothesis predicted that positive correlations would be found between consultant attempts to influence (i.e., domineeringness) and successful influence (i.e., dominance) and ratings on the three outcome measures. However, analyses failed to indicate significant relationships 
between these variables. The second hypothesis predicted that negative correlations would result between teacher domineeringness and dominance and the outcome measures. Again, none of the hypothesized relationships was significant. The lack of statistical support for these hypotheses suggests that attempts to influence and demonstrated influence by consultant and teacher are not associated with perceptions of significant outcomes in CBC. Finally, the third hypothesis predicted that negative correlations would exist between parent domineeringness and dominance and the outcome measures. Statistical analyses indicated that the relationship between parent domineeringness and the outcome measures was not significant. This lack of statistical support suggests that attempts made by a parent to control the process of consultation are not associated with significant perception-based outcomes of consultation.

Parent dominance, however, was found to be significantly related to two outcome measures, even when using a conservative alpha level. Twelve possible comparisons were examined (two dyads $\times$ six outcome measures), and three correlations were found to be significant. The first finding was that, within the parent-consultant dyad, parental influence over consultants (i.e., dominance) was related to less favorable teacher ratings regarding the acceptability/effectiveness of CBC $(r=-49)$. More simply, as parents influenced the parent-consultant dyadic relationship, teachers rated the acceptability/effectiveness of $C B C$ lower. More interesting, this finding suggests that verbal behavior within a dyad is related to the perceived outcomes of an individual who is outside that dyad. It appears that when teachers observe parents exert influence over consultants, teachers perceive $C B C$ as less acceptable and effective. One explanation may be that teacher acceptability/effectiveness of $\mathrm{CBC}$ is lower because their expectations of the model are not met because of the nature of the parent-consultant interactions; that is, perhaps teachers expect and want consultants to be more influential regarding the direction that the CPII takes.

The second finding indicated that parent dominance within the parent-consultant dyad was associated with less favorable parent ratings of client goal attainment $(r=-.62)$. Similarly, the third significant finding indicated that parent dominance within the parent-teacher dyad was associated with less favorable parent ratings of client goal attainment $(r=$ -.58). These two findings together suggest that parental influence within the CPII is associated with less client progress toward the goal behavior, as perceived by the parent. In other words, as parents influence participants within the CPII, they report less positive behavior improvements for their child. 
Two possible explanations may relate to this finding. First, a higher level of parental dominance may indicate that parents view consultation as more an opportunity to gain social support than to engage in active problem solving; that is, a parent may frequently seek information and encouragement from a consultant and teacher as a means of support, with problem solving seen as a secondary function of consultation. For consultees to seek and obtain support is certainly a valid goal of consultation (cf. Erchul \& Martens, 2002), albeit one that is not always promoted by models of consultation that emphasize the goal of problem solving. Second, previous research suggests problem identification is a critical component of successful consultation (Bergan \& Tombari, 1976). The display of parent dominance within the CPII may interfere with adequate problem identification, particularly if interview objectives are not fully met. Given the high percentage of objectives met in the reported cases, however, this explanation appears less likely.

There are now two investigations that calculated CPII domineeringness and dominance scores for all CBC participants: Erchul et al. (1999) and this study. When comparing consultant dominance scores across these two studies, consultants in this study appear to have slightly higher domineeringness scores than those in Erchul et al. (1999). However, in both studies, consultants demonstrated strikingly similar levels of dominance toward parents and teachers. In addition, the pattern of parent dominance in this study appears to be much more similar to consultant dominance than in Erchul et al. (1999), suggesting that the acceptance of parent directiveness by teachers and consultants is very similar to the acceptance of consultant directiveness by parents and teachers. Furthermore, in this study, the level of teacher-to-consultant dominance is consistent with consultant and parent dominance, suggesting that, within specific dyads, these participants are sharing in the exchange of information that influences problem solving. It is possible that the adoption of shared roles characterized by coinfluence within a consultation interaction is one indication of collaboration. However, further research is needed to discern the relationships among influence, collaboration, and other relational communication terms as well as to document how the display of influence may differ qualitatively for all CBC participants.

Another important step in integrating the results of this study with the existing school consultation literature is to consider the issues involved in the "collaboration versus control debate" (Erchul, 1999; Gutkin, 1999). This debate is primarily concerned with the behavior of the consultant (i.e., 
interpersonal control) during consultation and the historical view that consultation is, or should be, a collaborative process. In short, a line of research by Erchul and his colleagues has provided empirical evidence that when consultants verbally direct the process of behavioral consultation, consultees report successful consultation outcomes, such as feeling satisfied and helped as a result of consultation. Other researchers (e.g., Fuchs, Fuchs, Bahr, Fernstrom, \& Stecker, 1990) demonstrated positive client behavioral outcomes. As a challenge to these interpretations, Gutkin (1999) provided alternate explanations of these studies that attempt to describe the consultant-consultee relationship as collaborative. However, as both sides of the debate have acknowledged, the interchange is weakened because there are no universally accepted definitions for some of the central terminology used in the debate, such as collaboration (see Schulte \& Osborne, this issue).

Findings involving consultee relational control have also been important to the collaboration debate. Recalling that teacher attempts to control the process of behavioral consultation have been associated with less favorable outcomes (e.g., Erchul, 1987; Erchul \& Chewning, 1990; Witt et al., 1991), the results of this study offer some support for the previous research and appear to question Gutkin's (1999) interpretation that consultee leadership (i.e., a concept similar to dominance) is unrelated to less favorable outcomes. Interestingly, within $C B C$, it is parent rather than teacher relational control that appears to be associated with negative outcomes, as results here indicated that parent dominance is associated with less favorable perceptions of child improvement by the parent and lowered ratings of acceptability/effectiveness of $C B C$ by the teacher. Furthermore, these findings introduce a new idea into the debate by suggesting that control within consultee-to-consultee relationships may be related to less favorable outcomes. Clearly, the implications of this result for the debate, which has previously focused on consultant-consultee relationships, is an area that requires further examination.

\section{Limitations}

There are some limitations to consider when interpreting this study's results. A primary limitation is the relatively low statistical power. Although CPIIs from 20 CBC cases were employed-a considerably larger data set than used in many previous $C B C$ studies-a much larger sample size is often needed to detect small-and medium-size effects (Cohen, 1992). For example, in a study with an alpha level of 0.05 , sample size of 20 , and an average effect size of 0.3 , the power yielded is 0.25 . Using a much more 
conservative alpha of 0.01 , the yielded power is 0.09 (Cohen \& Cohen, 1983). Clearly, the sample size of this study suggests that low power may have contributed to the failure to find significant relationships.

A second limitation is the use of self-report outcome measures. Although it may be important to recognize participant perceptions of outcomes, these perceptions may not necessarily be accurate reports of true behavior. It is possible that outcome ratings may have been affected by something outside of the consultative relationship, such as social desirability. This issue may be particularly important for parents, whose patterns of behavior and perceptions within $C B C$ have not been well established.

In addition, Sheridan et al. (2001) articulated several limitations of the larger data set from which the data in this study were taken. Relevant to this study is the limited external validity of the CBC cases. Consultants were graduate students who received intensive training in $\mathrm{CBC}$. As such, groups of consultants spent numerous hours across 4 years implementing $\mathrm{CBC}$ with teachers and parents who volunteered to participate. Sheridan et al. noted that it is unlikely practitioners would have received extensive training or have the time to implement $\mathrm{CBC}$ as comprehensively as occurred in research studies. The types of limitations that tend to limit external validity are frequently observed in efficacy studies and clinical trials (Kratochwill \& Stoiber, 2000). Efficacy studies typically involve the implementation of interventions in carefully controlled conditions rather than in actual practice conditions. Although the data collection reported by Sheridan et al. (2001) demonstrates some aspects of how practitioners might implement CBC (e.g., interviews occurred in classrooms, clients presented a range of difficulties), it is likely that practicing school psychologists would judge the conditions within the research study to be nearly optimal and therefore unrealistic in daily practice.

Given the general lack of research examining parental relational influence, it appears that this is a fertile area for exploration. Because parents and psychologists do not generally engage in a type of dyadic consultative relationship that occurs between teachers and psychologists in behavioral consultation, parent-teacher conferences may serve as an interesting comparison of parental influence in dyads versus triads. Although parent-teacher conferences do not typically follow a recognized model, many of these conferences are intended to serve a problem-solving function. Parental influence may also be observed during school-based multidisciplinary team or IEP team meetings. Because these meetings may result in a formal decision regarding the education of a child, it may be interesting to investigate the role of a parent with respect to relational control in this context (Erchul, 1992b). 


\section{Conclusion}

In closing, this study attempted to apply specific constructs from relational communication theory to $\mathrm{CBC}$ and to examine the relationships between these constructs and $\mathrm{CBC}$ outcomes. As evidenced by the research findings in this study as well as those in Erchul et al. (1999) and Sheridan et al. (2002), the nature of verbal interactions with respect to content and process is complex. Given the likelihood that more and more practitioners are being trained in the relatively new model of $C B C$, continued research focusing on the verbal interactions of this interview-based intervention is encouraged.

\section{ACKNOWLEDGMENTS}

This article is based on a poster presented at the annual convention of the American Psychological Association, San Francisco, August 2001. This poster, in turn, was based on a dissertation by the first author directed by the second author, with original data and considerable assistance supplied by the third author.

We thank the many consultants, teachers, parents, and students who participated, as well as Kristen Wilson and Deborah Mettler, who served as coders of consultation interviews.

\section{REFERENCES}

Bergan, J. R., \& Kratochwill, T. R. (1990). Behavioral consultation and therapy. New York: Plenum.

Bergan, J. R., \& Tombari, M. L. (1975). The analysis of verbal interactions occurring during consultation. Journal of School Psychology, 13, 209-226.

Bergan, J. R., \& Tombari, M. L. (1976). Consultant skill and efficiency and the implementation and outcomes of consultation. Journal of School Psychology, 14, 3-14.

Bronfenbrenner, U. (1977). Toward an experimental ecology of human development. American Psychologist, 32, 513-529.

Brown, D. (1993). Defining human service consultation. In J. E. Zins, T. R. Kratochwill, \& S. N. Elliolt (Eds.), Handbook of consultation services for children (pp. 46-64). San Francisco: Jossey-Bass.

Busse, R. T, Kratochwill, T. R., \& Elliott, S. N. (1995). Meta-analysis for single-case consultation outcomes: Applications to research and practice. Journal of School Psychology, 33, 269-285.

Cardillo, J. E., \& Sinith, A. (1994). Reliability of goal attainment scores. In T. J. Kiresuk, A. Smith, \& J. E. Cardillo (Eds.), Goal attainment scaling: Applications, theory, and measurement (pp. 213-242). Mahwah, NJ: Lawrence Erlbaum Associates, Inc.

Christenson, S. L., \& Conoley, J. C. (Eds.). (1992). Home-school collaboration: Enthancing children's academic and social competence. Silver Spring, MD: National Association of School Psychologists.

Cohen, J. (1992). A power primer. Psychological Bulletin, 112, 155-159. 
Cohen, J., \& Cohen, P. (1983). Applied multiple regression/correlation analysis for the behavioral sciences (2nd ed.). Hillsdale, NJ: Lawrence Erlbaum Associates, Inc.

Colton, D. L., \& Sheridan, S. M. (1998). Conjoint behavioral consultation and social skills training: Enhancing the play behaviors of boys with attention deficit hyperactivity disorder. Journal of Educational and Psychological Consultation, 9, 3-28.

Courtright, J. A., Millar, F. E., \& Rogers-Millar, L. E. (1979). Domineeringness and dominance: Replication and expansion. Communication Monographs, 46, 179-192.

Elliott, S. N., \& Von Brock Treuting, M. (1991). The Behavior Intervention Rating Scale: Development and validation of a pretreatment acceptability and effectiveness measure. Journal of School Psychology, 29, 43-51.

Erchul, W. P. (1987). A relational communication analysis of control in school consultation. Professional School Psychology, 2, 113-114.

Erchul, W. P. (1992a). On dominance, cooperation, teamwork, and collaboration in school-based consultation. Journal of Educational and Psychological Consultation, 3, 363-366.

Erchul, W. P. (1992b). Social psychological perspectives on the school psychologist's involvement with parents. In F. J. Medway \& T. P. Cafferty (Eds.), School psychology: A social psychological perspective (pp. 425-448). Hillsdale, NJ: Lawrence Erlbaum Associates, Inc.

Erchul, W. P. (1999). Two steps forward, one step back: Collaboration in school-based consultation. Journal of School Psychology, 37, 191-203.

Erchul, W. P., \& Chewning, T. G. (1990). Behavioral consultation from a request-centered relational communication perspective. School Psychology Quarterly, 5, 1-20.

Erchul, W. P., Covington, C. G., Hughes, J. N., \& Meyers, J. (1995). Further explorations of request-centered relational communication within school consultation. School Psychology Review, 24, 621-632.

Erchul, W. P., Hughes, J. N., Meyers, J., Hickman, J. A., \& Braden, J. P. (1992). Dyadic agreement concerning the consultation process and its relationship to outcome. Journal of Educational and Psychological Consultation, 3, 119-132.

Erchul, W. P., \& Martens, B. K. (2002). School consultation: Conceptual and empirical bases of practice. New York: Plenum.

Erchul, W. P., \& Schulte, A. C. (1990). The coding of consultation verbalizations: How much is enough? School Psychology Quarterly, 5, 256-264.

Erchul, W. P., Sheridan, S. M., Ryan, D. A., Grissom, P. F., Killough, C. E., \& Mettler, D. W. (1999). Patterns of relational communication in conjoint behavioral consultation. School Psychology Quarterly, 14, 121-147.

Fine, M. J. (1980). Handbook on parent education. New York: Academic.

Fine, M. J. (1989). The second handbook on parent education. New York: Academic.

Fuchs, D., Fuchs, L. S., Bahr, M. W., Fernstrom, P., \& Stecker, P. M. (1990). Prereferral intervention: A prescriptive approach. Exceptional Children, 56, 493-513.

Galloway, J., \& Sheridan, S. M. (1994). Implementing scientific practices through case studies: Examples using home-school interventions and consultation. Journal of School Psychology. 32, 385-413.

Gutkin, T. B. (1999). Collaborative versus directive/prescriptive/expert school-based consultation: Reviewing and resolving a false dichotomy. Journal of School Psychology, 37, 161-190.

Heatherington, L. (1985, August). Descriptive and lag analysis of relational control in counseling. Paper presented at the annual convention of the American Psychological Association, Los Angeles, CA. 
Heatherington, L., \& Friedlander, M. L. (1987). Family relational communication control coding system manual. (Available from Laurie Heatherington, Psychology Department, Williams College, Williamstown, MA, 01267)

Heatherington, L., \& Friedlander, M. L. (1989). Analyzing relational control in family therapy interviews. Journal of Counseling Psychology, 36, 139-148.

Henning-Stout, M. (1993). Theoretical and empirical bases of consultation. In J. E. Zins, T. R. Kratochwill, \& S. N. Elliott (Eds.), Handbook of consultation services for children (pp. 15-45). San Francisco: Jossey-Bass.

Hughes, J. N. (1992). Social psychology foundations of consultation. In F. J. Medway \& T. P. Cafferty (Eds.), School psychology: A social psychological perspective (pp. 269-303). Hillsdale, NJ: Lawrence Erlbaum Associates, Inc.

Kiresık, T. J., Smith, A., \& Cardillo, J. E. (Eds.). (1994). Goal attainment scaling: Applications, theory, and measurement. Hillsdale, NJ: Lawrence Erlbaum Associates, Inc.

Kratochwill, T. R., Elliott, S. N., \& Busse, R. T. (1995). Behavior consultation: A five-year evaluation of consultant and client outcomes. School Psychology Quarterly, 10, 87-117.

Kratochwill, T. R., Sheridan, S. M., Carrington Rotto, P., \& Salmon, D. (1991). Preparation of school psychologists to serve as consultant for teachers of emotionally disturbed children. School Psychology Review, 20, 530-549.

Kratochwill, T. R., \& Stoiber, K. C. (2000). Empirically supported interventions: Announcing a new section. School Psychology Quarterly, 15, 9-15.

Leaper, C. (1991). Influence and involvement in children's discourse: Age, gender, and partner effects. Child Development, 62, 797-811.

O'Keefe, D. J., \& Medway, F. J. (1997). The application of persuasion research to consultation in school psychology. Journal of School Psychology, 35, 173-193.

Rogers, L. E., \& Farace, R. V. (1975). Analysis of relational communication in dyads: New measurement procedures. Human Communication Research, 1, 222-239.

Rogers-Millar, L. E., \& Millar, F. (1979). Domineeringness and dominance: A transactional view. Human Communication Research, 5, 238-246.

Sheridan, S. M. (1997). Conceptual and empirical bases of conjoint behavioral consultation. School Psychology Quarterly, 12, 119-133.

Sheridan, S. M., \& Colton, D. L. (1994). Conjoint behavioral consultation: A review and case study. Journal of Educational and Psychological Consultation, 5, 211-228.

Sheridan, S. M., Eagle, J. W., Cowan, R. J., \& Mickelson, W. (2001). The effects of conjoint behavioral consultation: Results of a 4-year investigation. Journal of School Psychology, 39, 361-385.

Sheridan, S. M., \& Erchul, W. P. (1995). Consultee Final Perceptions Form (CEFPF). Unpublished scale. Salt Lake City: University of Utah; and Raleigh: North Carolina State University.

Sheridan, S. M., \& Kratochwill, T. R. (1992). Behavioral parent teacher consultation: Conceptual and research considerations. Journal of School Psychology, 30, 117-139.

Sheridan, S. M., Kratochwill, T. R., \& Bergan, J. R. (1996). Conjoint behavioral consultation: A procedural manual. New York: Plenum.

Sheridan, S. M., Kratochwill, T. R., \& Elliott, S. N. (1990). Behavioral consultation with parents and teachers: Delivering treatment for socially withdrawn children at home and school. School Psychology Reoiew, 19, 33-52.

Sheridan, S. M., Meegan, S. P., \& Eagle, J. W. (2002). Assessing the social context in initial conjoint behavioral consultation interviews: An exploratory analysis investigating processes and outcomes. School Psychology Quarterly, 17, 299-324. 
Sheridan, S. M., Salmon, D., Kratochwill, T. R., \& Carrington Rotto, P. J. (1992). A conceptual model for the expansion of behavioral consultation training. Journal of Educafional and Psychological Consultation, 3, 193-218.

Tracey, T. J., \& Miars, R. D. (1986). Interpersonal control in psychotherapy: A comparison of two definitions. Journal of Clinical Psychology, 42, 585-592.

Von Brock, M. B., \& Elliott, S. N. (1987). Influence of treatment effectiveness information on the acceptability of classroom interventions. Journal of School Psychology, 25, 131-144.

Weiner, R. K., Sheridan, S. M., \& Jenson, W. R. (1998). The effects of conjoint behavioral consultation and a structured homework program on math completion and accuracy in junior high students. School Psychology Quarterly, 13, 281-309.

Witt, J. C., Erchul, W. P., McKee, W. T., Pardue, M. M., \& Wickstrom, K. F. (1991). Conversational control in school-based consultation: The relationship between consultant and consultee topic determination and consultation outcome. Journal of Educational and Psychological Consultation, 2, 101-116.

Priscilla F. Grissom, PhD, is a School Psychologist with the Wake County (NC) Public School System. Her main research interest is teacher and conjoint behavioral consultation. She received her PhD from North Carolina State University in 2001.

William P. Erchul, PhD, ABPP, is a Professor of Psychology and the Director of the School Psychology Training Program at North Carolina State University. His main research interest is interpersonal processes and outcomes associated with psychological consultation. He received his PhD from the University of Texas at Austin in 1984.

Susan M. Sheridan, PhD, is a Professor of Educational (School) Psychology at the University of Nebraska-Lincoln. Her primary research interests are in the areas of home-school partnerships, conjoint behavioral consultation, and social skills interventions. Dr. Sheridan, the current Editor of School Psychology Review, received her PhD in 1989 from the University of Wisconsin-Madison. 